\title{
RE-CONFIGURING WORKFLOW MANAGEMENT SYSTEMS TO FACILITATE A "SMOOTH FLOW OF WORK"
}

\author{
H.A. REIJERS \\ Eindhoven University of Technology, Department of Technology Management, PAV D-14, \\ Eindhoven, PO Box 513, The Netherlands \\ h.a.reijers@tm.tue.nl \\ S. POELMANS \\ Vlekho Business School, Department of Business Economics, Koningsstraat 336, \\ Brussels, 1030, Belgium \\ Stephan.poelmans@vlekho.wenk.be
}

\begin{abstract}
The image of workflow systems as being context-insensitive technology, hindering rather than supporting people in performing their work may still exist at present. This impression is also raised in the well-known and often cited case study within Establishment Printers. Using this case as a starting point, this paper presents an analysis of more recent workflow implementations to support the view that modern workflow systems are widely applied in the services industry and are considered useful by performers to support their way of working. In cases where the introduction of workflow technology initially disrupted the flow of work, a wide range of configuration options was available to mend such situations. A detailed analysis of a workflow implementation in a Belgian financial organization clearly shows that re-configuration decisions, like a finer step granularity, can transform a pre-structured production-type workflow system into a flexible application allowing and supporting a smooth flow of work.
\end{abstract}

Keywords: Workflow management systems; Business process management; Enterprise systems; End-user effectiveness; Field study.

\section{Introduction}

In recent years, many case studies have been reported on the application of workflow technology in actual organizational settings. This sharply contrasts with the situation over a decade ago. At that time, the lack of empirical studies of workflow and groupware technology was identified as a critical problem in designing and implementing automated support for cooperative work (Bowers, 1994; Orlikowski, 1992).

One of the well-known case studies that emerged in response to this need involved the introduction of the workflow system PF2 within Establishment Printers (EP). This study, as first described by Bowers, Button and Sharrock (1995), is now one of the most influential studies in the field (see for example Dourish et al., 1996; Poelmans, 1999; Lousa, Sarmento and Machado, 2000; Aversano et al., 2002, Reijers, Rigter and Van der Aalst, 2003). A recent consultation of scholar.google.com revealed that it is cited in more than 160 research publications ${ }^{1}$. The study is considered as an exceptionally relevant

${ }^{1}$ Consulted on April 14, 2006. 
example of a "critical case" in IS research (Rolland and Herstad, 2000), in the sense that it is a case of particular interest and with strategic content in relation to the research questions investigated. This can also be concluded from its frequent re-use to present new perspectives and frameworks (e.g. Dourish, 2001).

The EP case study is often used to illustrate the practice of imposing contextinsensitive technology on the way people work (e.g. Ljungberg et al., 1997; Harris and Henderson, 1999). For those within the CSCW community who oppose the view on work as something that can be formally predefined, it is also a welcome support of their arguments. It must be stressed here that Bowers et al. themselves draw very balanced conclusions from their work. It is true that they ask for more attention to the factors that generally make technology acceptable in an actual organizational context. In addition, with respect to workflow technology, they state that such systems may still be reasonable solutions when the list of provisos a company has to account for is tolerably short.

In this paper we will start with the findings of the EP case study, because it raises some interesting questions with respect to:

- the kind of work that lends itself for workflow support, and

- the effects of particular configuration decisions on the success of a workflow implementation.

These questions will recur in the analysis of a number of workflow implementations that we have been involved in ourselves over the past years. In the first place, we will establish that the common habitat for workflow systems is the service industry, rather than settings such as the EP case where physical goods are produced. Secondly, we will show that the studied projects showed similar disruptions in the early stages (after the roll-out) as the EP case did. However, after one or more re-configuration(s), i.e. technical changes to the existing workflow implementation, a number of significant difficulties were resolved. In this paper we will consider various technical changes of a workflow implementation, such as a finer granularity of steps in the process model and a wider access for performers to the in-trays of other performers. In this way we hope to shed some light on the factors that determine the success of workflow implementations, both from an organizational and, mainly, from an end-user perspective.

The structure of this paper is as follows. First we will summarize the EP case study. This summary will particularly address the flexibility that workers apply to get their work done, as well as the difficulties they faced when the workflow system became effective. Then, we will reconsider the EP case, selecting the most crucial disturbances and identify potential configuration issues that could cause such disturbances in general. Finally, we will project certain disturbances on our own empirical findings and show how they have been solved. We will end this paper with our conclusions. 


\section{The EP Case}

The first report on the use of the PF2 workflow system by an UK-based organization called Establishment Printers (EP) is, as stated in the introduction, by Bowers et al. (1995). EP engages in a variety of forms of print production work. A range of jobs enter the workplace which are being processed by human operators using all kinds of technology, from traditional hot-metal presses to digital reprographic machines. About the variability in the kind of print work the researchers say the following (p.54):

“[EP] may receive little notice of work which may itself have varying degrees of importance to the customer. Additionally, the work can run to different deadlines. [...] Furthermore, very little of the scheduling of when jobs come in is under the direct influence of EP themselves."

To deal with this inherent variability, EP personnel is organizing their work so that there is "a smooth flow of work through the shop floor". We will describe these work practices in some more detail and then take a look at the constraining effects on these practices by the introduction of the workflow technology.

According to Bowers et al. (1995), there are four major ways how EP personnel ensures that there is a smooth flow of work on the shop floor:

(p1) Prioritizing Work. Both the allocation of jobs to operators and the order in which jobs are being processed by these operators is dynamically determined. The allocation of work takes the availability and skill of the operators into account. The priority of a job is determined by its due date, its labor intensiveness, and its possibilities to be simultaneously processed with another job.

(p2) Anticipating Work. When this is beneficial, known-in-advance jobs are scheduled, prepared for, or even executed before the actual order arrives or before the information on the job is complete.

(p3) Supporting Each Other's Work and Knowing the Machines. Workers may support each other on an ad-hoc basis in carrying out each other's tasks, as they are attentive to each other's workloads and the signals and noises of the machines.

(p4) Identifying and Allocating Interruptible Work. Jobs may be dynamically split-up into smaller ones. When idle, non-operator staff may be allocated jobs, preferably jobs that are non-urgent, simple, and interruptible when they have to become active in their own work setting.

The introduction of the PF2 system disrupted the smooth flow of work as accomplished by the four mentioned practices. Bowers et al. (1995) distinguish the following four constraints that the workers faced, even a year after the implementation of PF2:

(c1) The Imposition of Procedure. The PF2 system imposes the procedure that work must be registered first, before it can be accomplished. 
(c2) Work as Processes in Series. A single operator cannot engage in more than one job at a time.

(c3) The Overhead of Use. The administration of small jobs in PF2 is a proportionally big overhead.

(c4) The Individualization of Work. The execution of a job can only be attributed to one operator.

The EP case study continues with a description of how the staff at EP copes with these problems, as they are required to continue to use $\mathrm{PF} 2$ due to contractual agreements. Although there are interesting things to be learned from these so-called "coping strategies" (Dourish, 2001), we will focus on the misfit between work practice and automated support. We will first perform an analysis on the EP case study to identify some issues that seem worthwhile to consider in our own case studies.

\section{A desk analysis of the EP case}

A first observation that can be made about the EP case is perhaps easily overlooked. Although the coping strategies that Bowers et al. (1995) describe indeed address the constraints as we described in the previous section, it is not obvious how the constraints themselves violate the "smooth flow of work" practices that were identified. One major work practice, 'identifying and allocating interruptible work' (p4), is not being discussed at all, so it is unclear whether non-operator staff is still being able to perform the work of operators when they are idle or not.

With respect to the other practices, it still seems possible to do the following:

- To take the availability and skill of operators into account in dynamically allocating jobs to operators (p1),

- To use the labor intensiveness and due date as a job priority criterion (p1),

- To use the signals and noises of machines to have an operator select the next thing to do (p3), and

- To take over the work of another operator (p3).

It should also be noted that the 'overhead of use' constraint (c3) is not truly jeopardizing any work practice. It is so that it generates extra work, but it is not affecting any of the practices mentioned. It seems clear to us that it is inevitable that to get something extra from a system - current management information - some extra effort has to be paid: "There is no such thing as a free lunch".

So, a preliminary conclusion could be that the infringement on the smooth flow of work caused by the workflow technology of PF2 is only partial.

Nonetheless, the resulting constraints - or parts of these constraints - are truly experienced as jeopardizing the current working practice. More specifically, because the PF2 system imposes the procedure that work must be registered first before it can be accomplished (c1), it requires a workaround to 'jump the gun' (anticipate work) (p2). Secondly, because single operators are not allowed to engage in more than one job (c2), it 
prevents them to carry out jobs simultaneously (p1). Finally, because the execution of a job can only be attributed to one operator, it cannot be accounted for when one operator dynamically engages in a job of another operator (p3). These are the infringements we will inspect more closely.

\subsection{Jumping the Gun}

The principle of 'jumping the gun' refers to the practice of anticipating work (p2). As stated earlier, this means that known-in-advance jobs can be scheduled, prepared for, or even executed before the actual order arrives or before the information on the job is complete.

A question that comes to mind is whether this practice is perhaps much more common in manufacturing, where physical products are produced, than in the context of administrative processes, which primarily deal with intangible goods. After all, there are subtle differences between the logistic properties of the business processes in these domains (see e.g. Platier, 1996; Van der Aalst and Berens, 2001).

To us, 'jumping the gun' seems particularly applicable when the work that is being done is not dependent on the precise characteristics of the order for this job. This is the case for many physical goods. Consider, for example, a product like a bicycle. In many cases, a customer will visit a bicycle shop and choose one from the many available items in stock. But, that particular bicycle has been produced without any particular knowledge of the customer who buys it. So, production has preceded the order here. More in general, for many physical products being manufactured it may be unknown for quite a while to which order it will eventually be matched (if any). Obviously, this creates opportunities to work ahead of actual orders, as is also demonstrated in the EP case.

In an administrative setting, in contrast, this is less feasible. Try to imagine a local government that produces building permits for citizens ahead of the specific requests for these permits. Customers may enter the city hall and simply pick up one of the preproduced permits. This is clearly out of the question. The name of the citizen, the location of the future building, the building's dimensions, etc. are all essential ingredients to produce the permit or even to start considering its issuing. In service settings, it is often the case that the order must often precede the production (e.g. a request for a mortgage, a work permit, a piece of legal advice, etc.). Obviously, even in administrative setting work anticipation is possible to some extent. The financial case study that we describe later in this papers offers such an example. But it seems clear that the opportunities are fewer than in manufacturing settings. Note that from a logistical point of view the described difference between manufacturing and administrative processes can be understood in terms of the position of the customer-order decoupling point (Giesberts and Van der Tang, 1992).

We tentatively conclude that workflow systems may be more at their place in administrative settings, where there is a clear relation between work and the specific case for which it is executed. The problems that are associated with supporting the anticipation of work in the EP case are therefore perhaps not felt so severely in the service industry. 


\subsection{Simultaneous Scheduling}

As explained before, after the introduction of the workflow technology for the EP case it became impossible to schedule labor-intensive and machine-intensive jobs simultaneously for the same operator. A question that occurred to us is whether this problem can be related to the level of detail that jobs have been distinguished with, rather than to characteristics of the workflow technology itself. Please consider the example in Figure 1.

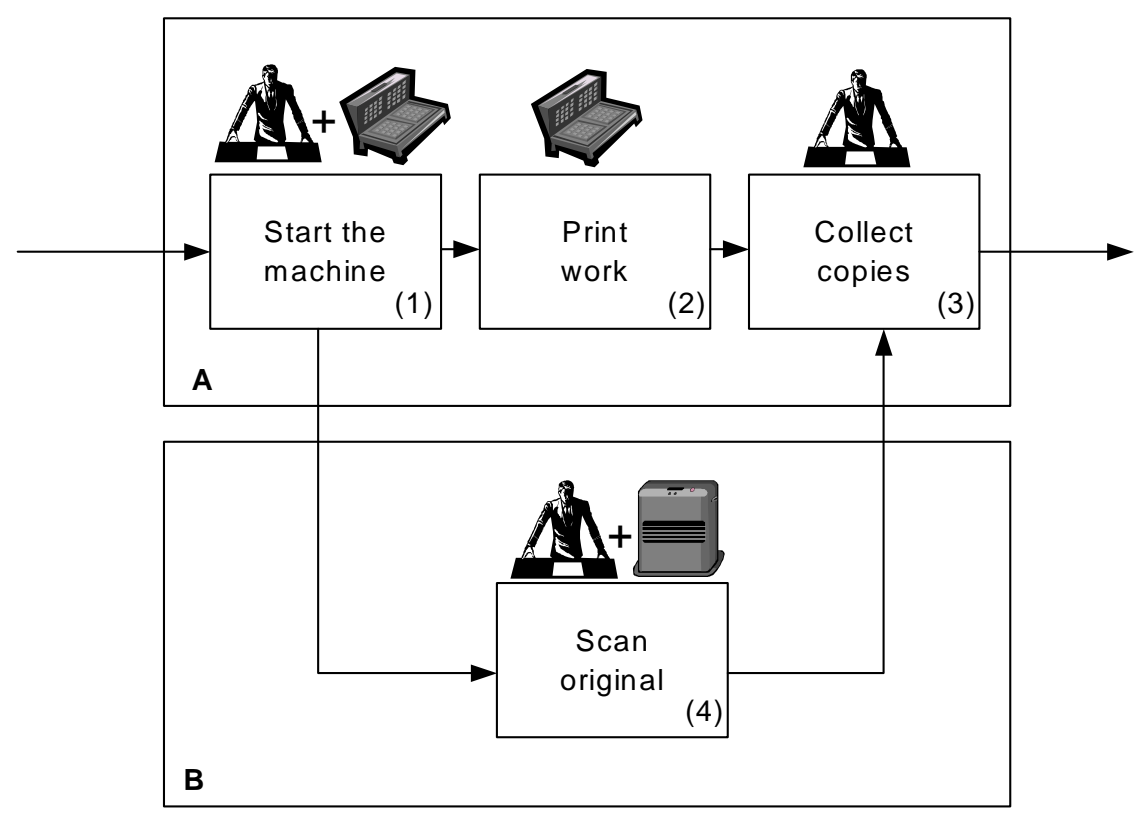

Figure 1. An example business process.

In this example, which is derived from the EP case study, two different jobs exist: A and B. Job A consists of three smaller operations, namely:

(i) Start the machine: An operator has to insert the original file into the digital photocopier and then specifies the number of copies, the format, and the quality

(ii) Print work: The digital photocopier reproduces the digital original according to the previous instructions

(iii) Collect copies: The operator collects the copies and the original.

Job B consists of only one smaller operation, namely the scanning of another original image into a scanner (iv). Note that we have symbolically indicated alongside each step (job) what resources - operators and/or machines - are required for each of them. 
In the original situation, it was possible for the same operator to subsequently perform operations (i), (iv), and (iii). After all, the machine-intensive operation (ii) did not require the operator to be present. So, the two separate jobs A and B could be said to be performed simultaneously.

After the introduction of the workflow technology, the simultaneous execution of these jobs was not possible any more, as the workflow system counted the operator who performed operation () as busy with job A for the entire duration of operations (i), (ii), and (iii).

We can only speculate here that a problem is generated by the way work is divided. Although we do not know the specifics of the workflow system PF2, a typical characteristic of commercially available workflow systems is that they operate on the basis of a so-called process definition (Fischer, 2001). By representing a business process in the form of such a network of steps including the nature of the relations and the criteria to start and end these steps (the pre- and postconditions), designers specify how the workflow system enacts the process. One aspect of such a process definition is to define the boundaries of steps, which may then be handed out to workflow participants as work items (Fischer, 2001).

Although operations (i), (ii), and (iii) are strongly related, they should perhaps not be represented as one monolithic job. Rather, all operations should be represented as separate steps in the process definition, each of which may then be allocated separately as a work item by the workflow system to operators, machines, or combinations of them. This would allow the simultaneous execution of operations (ii) and (iv).

So, even though it is impossible to establish whether the proposed solution would have been feasible in the EP case let alone resolved the experienced problems, it seems clear that a more fine-grained view on work can alleviate problems with respect to the simultaneous scheduling practice.

\subsection{Dynamic Engagement}

The last real infringement of the "smooth flow of work" we distilled from the EP case is the inability to dynamically engage in jobs of other operators. In the paper, the following example is given (p.61):

"If a big job is done on a digital reprographics machine, say, by one operator replenishing the paper, while another unloads the copies from the stacker, while a third scans in the next ten pages, they have to discuss amongst themselves which of the three should appear as having done the work and which two potentially appear as idle."

To some extent, we may be looking here at a similar problem as the simultaneous scheduling issue discussed before. Why should large jobs be allocated completely to one operator? Again, it may be wiser in general to divide the process in the process definition into manageable parts that more naturally relate to what one operator may do in one uninterrupted action. In this area the application of the so-called ACID-properties known from transaction processing are favored to distinguish logical units of work (Van der 
Aalst and Van Hee, 2002), i.e. atomicity, consistency, isolation, and durability (Harder and Reuter, 1983). In practice, this means that a step (job) is indivisible and either carried out in full or not carried out at all.

Still, it should be acknowledged that the need for strict time accounting may inevitably result in problematic situations. After all, if the size of a job is determined by accounting considerations it does not necessarily need to coincide with the job size that is preferable from an execution perspective. It would be rather unfair to criticize workflow technology in general or the configuration of the system in the EP case study in particular for such mismatches. Bowers et al. themselves state that if there are good organizational reasons for accounting for the work in new and more detailed ways, a workflow system like PF2 is still a reasonable solution despite the various constraints it imposes, e.g. the proportionally big overhead of administering small jobs (c3). In other words, the inability to dynamically engage in jobs may very well be an inescapable result from stricter accounting demands, but not an intrinsic flaw of workflow technology.

In conclusion to this desk analysis, we can state that the EP case study reveals some notable infringements that may be experienced when introducing workflow technology on the work floor. At the same time, only part of the practices that ensured a smooth flow of work in the studied case were affected and some infringements should perhaps be seen as the price to be paid for other benefits, e.g. a stricter time accounting. This in itself is a more qualified perspective on the EP case study than is often raised in the sources citing it.

What is important for the remainder of this paper are two other issues we distinguished. First of all, we conjectured that the problems with workflow support that can be associated with the anticipation of work are perhaps not felt that severely within service companies, simply because there are less opportunities to 'jump the gun'. Secondly, we also raised the issue whether problems similar to those that were experienced in the EP case could be mended in other contexts by other configuration decisions, e.g. a finer granularity of steps in the process model. In the next section, we will examine these issues further.

\section{A field analysis of workflow implementations}

In the years 1996-2006, we have carried out three separate studies, which comprised 25 different workflow system implementations in 13 Dutch and Belgian companies (see Table 1). Overall, these studies covered implementations of different commercial workflow systems (Staffware, COSA, Visual Workflo, FLOWer, TeamWareFlow) and one proprietary system. The workflow projects were studied with different research methods and with different objectives. A first group (X) of 5 workflow implementations has been specifically studied to determine the degree of suitability of workflow systems from an end-user perspective (Poelmans, 2002). The second group (Y) of 17 workflow implementations focused on the quantitative effects of workflow management systems on organizational performance, such as process cycle time and resource occupation. This 
study is still in progress, for preliminary results see (Reijers and Van der Aalst, 2005). The third and final group $(Z)$ of 3 workflow implementations was recently studied to determine factors that influence the success of workflow implementations from an organizational perspective.

Table 1: An overview of the participating organizations and studied workflow implementations in studies $\mathrm{X}, \mathrm{Y}$, and Z.

\begin{tabular}{|c|c|c|c|c|}
\hline $\begin{array}{l}\text { Organization } \\
\text { number }\end{array}$ & $\begin{array}{l}\text { Organization } \\
\text { description }\end{array}$ & $\begin{array}{l}\text { Focus of involved } \\
\text { processes }\end{array}$ & $\begin{array}{l}\text { Number of involved } \\
\text { implementations }\end{array}$ & Part of study \\
\hline 1. & Financial corporation & $\begin{array}{l}\text { Commercial credits, } \\
\text { mortgages }\end{array}$ & 2 & $\mathrm{X}$ \\
\hline 2. & Local municipality & Call for tenders & 1 & $\mathrm{X}$ \\
\hline 3. & Research department & Information requests & 1 & $\mathrm{X}$ \\
\hline 4. & Utility company & Administration & 1 & $\mathrm{X}$ \\
\hline 5. & Governmental agency & Debt collection & 1 & $\mathrm{Y}$ \\
\hline 6. & Health insurer & $\begin{array}{l}\text { New applications, } \\
\text { policy maintenance }\end{array}$ & 7 & $\mathrm{Y}$ \\
\hline 7. & $\begin{array}{l}\text { Public works } \\
\text { department }\end{array}$ & Invoice processing & 1 & $\mathrm{Y}$ \\
\hline 8. & Local municipality & $\begin{array}{l}\text { Invoice processing, } \\
\text { purchasing }\end{array}$ & 2 & $\mathrm{Y}$ \\
\hline 9. & Insurance intermediary & $\begin{array}{l}\text { New applications, } \\
\text { policy maintenance }\end{array}$ & 4 & $\mathrm{Y}$ \\
\hline 10. & $\begin{array}{l}\text { Domiciliary care } \\
\text { agency }\end{array}$ & $\begin{array}{l}\text { Human resource } \\
\text { management }\end{array}$ & 2 & $\mathrm{Y}$ \\
\hline 11. & $\begin{array}{l}\text { Mobile telecom service } \\
\text { provider }\end{array}$ & Loyalty offers & 1 & $\mathrm{Z}$ \\
\hline 12. & Asset manager & $\begin{array}{l}\text { Investment advice } \\
\text { delivery }\end{array}$ & 1 & $\mathrm{Z}$ \\
\hline 13. & Retail bank & Services fulfillment & 1 & $\mathrm{Z}$ \\
\hline
\end{tabular}

Considering the 'acquisition' strategies for finding workflow implementations, we believe to have gained access to quite a representative sample of Western-European organizations currently implementing workflow systems. The selection of workflow implementations that were studied across the different research projects varied. For project X, we could study a sample of five business process within four different companies. We contacted several workflow vendors in Belgium, and also professional organizations related to the financial sector. We participated in project $\mathrm{Y}$ with a "Big Four" consultancy company. We contacted all the consultancy's client organizations in the Netherlands that were considering workflow implementations and asked them whether they were willing to participate. We also called for participation in advertisements in professional IT journals, which attracted some organizations which were not clients of the consultancy company. For project $Z$, we worked together with one the largest European workflow system vendors. We approached the four clients that most recently completed an implementation of the respective system and asked them to participate. Three of these companies complied. An analysis of the participating organizations in the various studies also points out that they include both commercial and 
not-for-profit organizations, ranging from medium-sized to large. The absence of smaller companies seems to be in line with a general insight that workflow systems are not costeffective on a small organizational scale.

\subsection{A Natural Workflow Habitat}

Interestingly, we can point out that all 13 organizations involved in studies $\mathrm{X}, \mathrm{Y}$, and Z are service organizations. As can be seen in more detail in Table 1, among these organizations were health insurance companies, financial institutions, a home care institution, municipalities, etc. Furthermore, in projects $\mathrm{X}$ and $\mathrm{Y}$, we were able to study the processes supported by workflow technology in much detail, which included an analysis of the work processes to be supported (steps, work procedures, job allocation policies, information exchanges, involved resources). The 22 processes in these two research projects involved the acceptance of new clients, the processing of invoices and mortgage requests, the collection of debts for traffic fines, the handling of mutations in insurance policies, the maintenance of human resources records (see Table 1).

It is interesting to note that the variability of work within some of the processes even seemed to exceed the described variability within the EP case. However, we observed the practice of the anticipation of work in only one of the cases we studied. The single exception has been the commercial credits process that will be discussed in the next section. We are obviously referring now to the situation before the workflow system was implemented, which was studied in detail in projects $\mathrm{X}$ and $\mathrm{Y}$.

We think our observation of all involved organizations to be service organizations is quite remarkable, underlining our earlier conjecture that workflow systems seem to belong de facto to the service domain. Obviously, it frequently happens in administrative settings that processes make progress although the information on the job is incomplete. In fact, we noted that many steps within the processes of handling application procedures for health insurance have to do with completing all the required information before an actual decision can be made. The bottom line is, however, that right from the start of the process in producing an administrative product the notion of the related order is clear. In other words, the order precedes production. Furthermore, in the cases where we identified incompleteness of information, the workflow technology offered flexibility to adapt to end-users' needs to deal with these issues, as will be illustrated in the next section.

\subsection{Implementation Success}

Overviewing the 25 workflow implementations we studied, we have observed that the vast majority of these were considered successful from a management perspective. As an illustration, for all three cases examined in study $\mathrm{Z}$, the business objectives that were formulated in the form of a business case prior to the project were considered by the management as realized at some point in time. Consider, as a representative example, a service provider for mobile telecommunications and mobile Internet that was involved in study Z. In 2002, the Dutch branch of this company employed approximately 700 people, 
served 1.4 million customers and achieved a turnover of $€ 520$ million. The main objective for introducing workflow management technology for this company was to drastically reduce the lead time of bringing out so-called 'loyalty offers'. There was no structured process available to offer an existing customer a new contract when a running contract was about to terminate. Instead of relying on the development and execution of ad-hoc actions that were taken by different people to bring out such offers, a structured process supported by workflow technology was introduced. This speeded up the process considerably and relieved the people involved from manually registering the actions they had taken with respect to specific customers. As a result, the number of loyalty offerings that can now be delivered within the same amount of time with the same number of resources as before is increased almost tenfold.

Note that we do not claim that such successes came at negligible cost in the cases we observed. We have seen overrunnings of project budgets (the telecom service provider we mentioned exceeded its project timeline with 15\%), end user issues and various technological difficulties, in particular the complicated integration of the workflow system with existing platforms. Yet, the business benefits of implementing workflow technology seemed to outweigh these difficulties for the involved management.

Our focus in this paper is, however, not on the business side, but to consider implementation success from the perspective of maintaining a smooth flow of work on the work floor. For this purpose, we choose to focus in this article on study X, which involved the analysis of five operational workflow implementations in four different service organizations. The study consists of two parts: an in-depth qualitative study of two automated business processes in an international financial corporation (Finco) and a survey analysis of these two business processes, together with three other business processes in three different organizations. These additional processes involved a "call for tender" process in a municipality, an information request process in a research department and an administrative process in a utility company.

The unit of analysis of the survey is the individual end-user of a workflow system. ${ }^{2}$ The suitability (success) of a workflow system is the dependent variable. It is defined as: "the degree to which a workflow system meets the job requirements of an end-user." 3 In the survey, this concept was primarily measured using the standardized measure of "perceived usefulness" 4 , while three additional survey questions with respect to overall satisfaction with the system were used to validate this measure.

In the qualitative case study, more than 40 interviews embody the IT perspective, the management's point of view and the perceptions of the end-users. These interviews were combined with many hours of observations and a study of the available documentation of

\footnotetext{
${ }^{2}$ The survey covered 528 end-users with a $38 \%$ response rate.

${ }^{3}$ The suitability of a workflow system was used in two explanatory models, including several factors, such as flexibility measures, task and process characteristics, support, etc.

${ }^{4}$ This measure has been introduced by Davis (1989) in his Technology Acceptance model (TAM).
} 
the workflow applications. The case study was longitudinal, conducted at three points in time $^{5}$

In order to reflect on the findings of Bowers et al. (1995), we want to focus on the qualitative case study, performed at Finco. More specifically, we will illustrate two issues, discussed earlier in this paper: the granularity of steps in the process definition (c2: 'work as processes in series') and the 'imposition of procedure' (c1).

The Granularity of Steps in the Process Definition: The two processes at Finco were not related to each other. A first process was called the "mortgage process". It comprised all the activities of the back-office, required to register, analyze and decide upon mortgage requests. The second process, the "commercial credits process", was an end-toend process, dealing with loan requests from medium-sized and large companies.

Both processes were automated with "Visual Workflo", known to be a productiontype of workflow technology. ${ }^{6}$ When comparing the two workflow applications, there is a clear difference in the level of detail of the defined steps (jobs) in the processes. The workflow application of the commercial credits process consisted of four major steps, allocated to three separate roles, i.e. types of employees (the account managers, the analysts and the decision-makers). One step could take up to one or two days. On the contrary, the mortgage process consisted of 11 smaller steps, requiring between 10 and 30 minutes each. In the mortgage process, four roles were defined: file managers, analysts, decision-makers and quality controllers.

\footnotetext{
${ }^{5}$ The interview protocols, the questionnaire and results are presented and discussed in (Poelmans, 2002).

${ }^{6}$ For the differentiation between ad-hoc, administrative and production workflow solutions, see Georgakopoulos, Hornick, and Sheth (1995).
} 

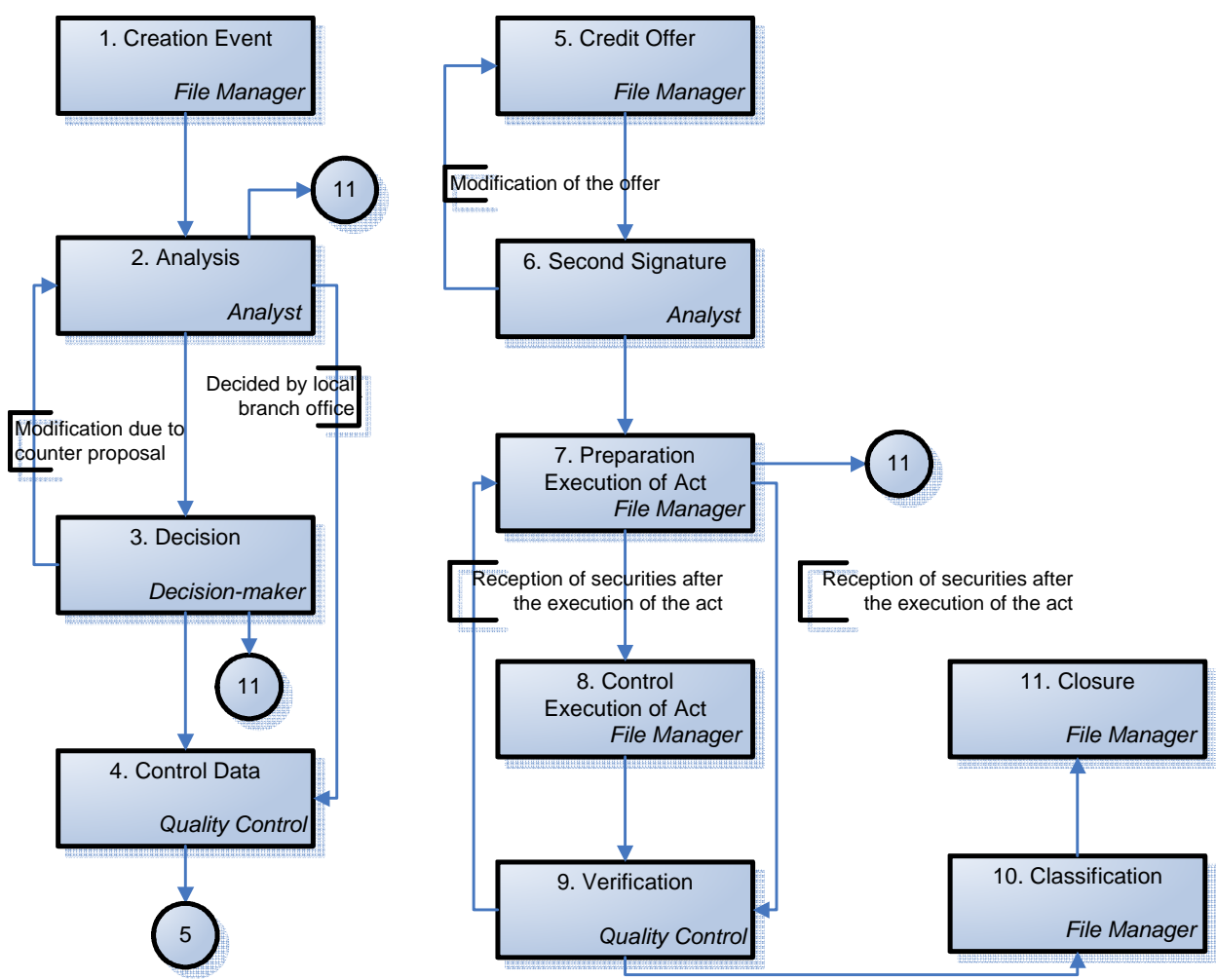

Figure 2: the Final Mortgage Process

The business process model as presented in figure 2 has been the result of several changes. Firstly, the original version of the workflow application had fewer steps. More specifically, steps 2 and 3 were at first implemented as activities to be handled in one step, by the same person. Because the "analyst" and the "decision-maker" turned out to be different persons at certain desks (and/or at certain periods), the role was split. Also step 7 and step 8 were perceived in the original set-up of the workflow system as one step. Because special securities were often required, an in-between verification was needed before the final "control of the execution of the act". Therefore "preparation" (step 7) and "control" (step 8) were re-configured as separate steps.

The division into detailed steps in the mortgage process, combined with a flexible step allocation procedure, resulted in a flexible workflow implementation. A file manager, the main role, could perform 8 out of the 11 steps. Although file managers could only open one request (file) at a time, they could easily return a file to their in-tray (with the status "on hold") and start with another request. This happened frequently as extra information such as legal documents or other data had to be requested from third parties or the mortgage applicant. 
A second important re-configuration was the accessibility of the in-trays for file managers. (Note that other roles also used in-trays for work distribution, but they are not considered here.) During the first months after the initial roll-out of the workflow system, file managers had personal in-trays. Because of different characteristics of the requests, but also because of differences between the file managers, workload problems occurred. For example, at the same time in-trays of some file managers could be empty while others were overloaded. Eventually, a technical re-configuration resulted in an application that allowed file managers within one desk to access the in-trays of other file managers (not of the other roles in the process), thus creating a virtual common in-tray. In order to create awareness of the state of the requests, efforts were also taken to add visual stimuli to the common in-tray, for instance, colored icons were used to indicate whether a request was "available", "on hold", etc.

Finally, the fine-grained step definition was also combined with a flexible configuration of the process logic or routing of files through the workflow system. Although a few steps were mandatory, other steps could be skipped and files could easily be sent back and forth within the process (see the possible iterations in figure 2).

The fine-grained and flexible configuration of the production workflow solution was quite a success, receiving very good comments from all interviewees. In the global survey, this workflow implementation also received the highest degree of "perceived usefulness". The flexibility of the implementation was actually provided to apply the workflow application into several regional divisions, each with their own work practices. We want to remark that file managers were arranged in desks, consisting of 6 to 10 file managers and one desk manager. The local desk managers often scheduled and organized the work. File managers, for example, did not always use all the possibilities/features of the workflow technology. In some desks, they were only allowed to process a limited number of steps. This meant that the flexibility in step allocation (doing several different steps in the process) and routing (the sequence of steps) was not always useful for the individual file managers. The possibility to easily (re-)distribute files (file allocation) within or even between desks, however, was a real requirement supporting the day-to-day activities.

Relating to the EP case study, the two following problems could be avoided in the case of Finco:

(c2) Work as Processes in Series. End-users could start a file (request), put it "on hold" if necessary, and start with another one. In the EP case, on the contrary, print jobs had to be finished before starting a new job. Moreover, because of the coarse-grained definition of a print job, it was not possible to redistribute a job to several shop workers

(c4) The Individualization of Work. By using roles, employees with the same job were grouped and files could easily be (re)assigned and distributed within and even between desks. The modeling of roles in a business process was not reported in the EP case, but it is a standard solution, provided by all the workflow systems that we encountered so far. 
The Imposition of Procedures versus Task Flexibility: During our first visit of the commercial credits process, the system was operational for about one year. At that time, the workflow system was being used by 100 end-users ${ }^{7}$, but not really accepted by each type of participant in the process, i.e. by all roles. We were able to study the two principal roles in the business process: (i) the account managers (acma's), who create requests in the workflow system, being the first step in the process and (ii) the analysts, analyzing the requests, being the second step in the process. Both roles represented $90 \%$ of all endusers.

By then, the management had received a positive global evaluation of the workflow implementation, indicating that the total process cycle time had decreased with $36 \%$, i.e. 9 days instead of the 14 days before the roll-out of the workflow technology.

Contrary to the mortgage workflow implementation, the commercial credits application did not have flexible routing features or step allocation. The process was configured around four global steps, allocated to four separate roles. Each role was assigned one particular step (job) and employees could only perform the step belonging to their role. This fixed structure, however, corresponded well with the nature of the process and did not cause any problems.

With respect to file allocation. i.e. the distribution of requests, there were differences between the roles. Since an acma had his own "portfolio" of clients, he was not allowed to access the "in-tray" of his colleagues. Analysts, in contrast, were organized in desks with 4 to 5 analysts on one desk and within one desk they used a common in-tray, accessible and visible to all analysts of the desk. Again, this arrangement was perceived as "suitable" by both acma's and analysts.

Nevertheless, whereas the analysts were to a considerable degree pleased with the workflow implementation, the acma's were not. During our first visit, we interviewed 11 acma's, in different sites of Finco, and nobody seemed to be satisfied. Most acma's used similar arguments, which we will describe in more detail now.

Before the implementation of the workflow system, the acma's used to interact with a mainframe database. When a loan request had to be entered in the system, the acma only had to fill in one or two global electronic 'sheets', identifying general data about the client (requester), the required amount of money, and the purpose of the loan. Analysts could open the request and make a profound analysis of the solvability and risk of the proposed business investment and the client. When the request was approved in the next decision step, more detailed credit modalities could be negotiated with the client (by the acma) and eventually entered into the system. With the arrival of the workflow system, acma's were forced to enter detailed credit modalities before the request was even analyzed. The acma's stated that these data would only be relevant if the global request was approved. At this first stage, clients were not yet thinking about those issues. As a result, the data that had to be entered were just rough estimates that had to be adjusted later in the process. Interviews with the management revealed that this was a deliberate strategy. They wanted to decrease the risk and have more complete information in the

${ }^{7}$ At the time of the second visit, the system was being used nation-wide, with more than 600 end-users. 
first step of the process. In that sense, the workflow implementation seemed to be an opportunity to standardize and change work practices. Although management acknowledged their "agenda", they were backed up by the ICT department, stating that completing a file (request) only after the decision step, would cause serious technical adaptations.

It took the acma's more than a year to have the system adjusted, but during our second and third visit, this adaptation had been completed. Acma's could now start by creating a request with minimal information and complete a request after the decision step and after a new negotiation with the client. As a result, there was a remarkable change in the "perceived suitability" of the system. Also, objective measures confirmed this improvement: the processing time of the acma's (of one request) decreased with $50 \%$ ( 2 days instead of 4 for one request), while the processing time of the other roles was not affected.

We defined this type of flexibility as "task flexibility", referring to the degree that the workflow system determines what and how a certain step (job) should be performed. In particular, task flexibility in a certain step of the process can be restricted by strictly imposing the required data and/or the access to extra tools or applications used to complete that step. In the commercial credits process, an increase in task flexibility was actually achieved by not forcing the acma to enter too much data too soon in the process.

The problem and solution stated above is closely related to the first constraint of the EP case study: "first register it, then do it" (c1). At EP, the problem occurred because workers needed to 'jump the gun' to enable a smooth flow of work. Although the commercial credits process is an administrative process, it was surprising to observe that the anticipation of work turned out to be a serious obstacle for the acma's. Contrary to the EP case study, acma's were not really facing the problem that a job (loan request) had to be registered before the arrival of the official written request, but still, the particular workflow implementation forced them to enter too much uncertain data, too soon in the process.

In the case reported by Bowers et al. (1995), this 'imposition of procedure' (c1), led to the development of workarounds such as the retrospective recording of the actual work in the workflow system, or the creation of 'gang jobs' (p. 61). During our first visit, we observed similar workarounds. Acma's either filled in financial data "at random" or they even avoided the workflow system by sending paper files to the analysts. Finally, however, a re-configuration of the WFS led to a successful application.

\section{Discussion}

We started this paper with a desk analysis of the EP case study and pointed out in the remainder that we encountered similar difficulties in our studies. Although situated in entirely different contexts than the EP case study, a number of those problems were solved by making different design issues and a re-configuration of the workflow system. We have made a case for more fine-grained views on workflow processes and also considered the 'jumping the gun' practice as less common in administrative settings. We 
can identify at least three types of skeptical comments that could be brought forward against all of this:

- "A more fine-grained task analysis as you are suggesting may easily bring along a new set of potential problems. Critiques of work rationalization traditionally indicate that the more detailed the analysis, the more rigid the structure tends to be."

- "It is ironic that you argue that workflow, a technology based on the importation of process models from manufacturing operations into administrative work, is more appropriate for administration than for manufacturing."

- "You cannot prove that the encountered kinds of problems could have been averted in the EP case study!"

Let us consider these objections one by one. Firstly, considering all our empirical studies into workflow implementations, we were unable to detect any major problems arising from a more fine-grained distinction of tasks or more flexible configurations as we are suggesting. On the contrary, the fine-grained and flexible re-configuration of the production workflow solution in the case of the mortgage application at Finco was quite a success.

Secondly, all the implementations we encountered were carried out in administrative settings, although we did not restrict our 'acquisition' of cases in this respect. Indeed, the activities of EP could be characterized by elements of both the manufacturing and the administrative world, with both order-driven jobs and jobs that can be made on stock. For the EP case, the workflow technology forced all the work within the order-driven paradigm. However, we do not think it is fair to criticize the technology for this, when an administrative environment seems to be the 'natural habitat' for workflow technology. Note that most commercial workflow management systems are based on the make-toorder paradigm (Van der Aalst and Van Hee, 2002).

Finally, relating to the third and most important critique perhaps: it is, in fact, not our purpose to state that the encountered kinds of problems could be averted in the EP case study. Indeed, it would be quite unrealistic to attempt this: the EP case study cannot be redone, we were not involved in it in the first place, and we are not aware of all its details (in particular with respect to the available configuration options of PF2). Instead, we have discussed a workflow implementation at Finco in considerable detail, showing that similar constraints as identified in the EP case study have been solved or prevented, even when using a production workflow system. Finco solved these constraints by accomplishing the following adjustments:

- Task flexibility: Providing a sufficient degree of freedom in carrying out tasks so that the 'imposition of procedure' constraint (c1) can be avoided or at least diminished;

- Flexible file allocation: Configuring the "in tray" in such a way that end-users can start more than one file at a time, in this way lifting the potential "work as processes in series' constraint (c2);

- Flexible task allocation: Providing an extensive degree of access to different steps for various roles in order to easily divide and even "distribute" the work according to the workload of individual employees, in this way countering the individualization of work' constraint (c4). 
Since the used workflow system (Visual Workflo) is generally considered as a production workflow system, we expected to encounter a rather rigid workflow application. In the mortgage process, however, we observed the opposite. Due to a specific re-configuration of the workflow system, a flexible process support application was the result. Although the same workflow tool was used in both processes at Finco, a different configuration led to two different applications, fitting two different business processes.

In Table 2 we present an overview of the adaptations that have been applied to both applications.

Table 2: Several adaptations of the Workflow Applications at Finco.

\begin{tabular}{|c|c|c|}
\hline Before & After* & Type of Flexibility \\
\hline \multicolumn{3}{|l|}{ Mortgage Process } \\
\hline 9 steps & 11 steps (more fine-grained) & Step granularity \\
\hline More "routing constraints" & $\begin{array}{l}\text { More iterations: routing forward and } \\
\text { backward between most of the steps }\end{array}$ & Routing \\
\hline Personal in-trays & $\begin{array}{l}\text { A shared in-tray for each desk (6 to } 10 \\
\text { file managers) } \\
\text { More visual aids to clarify the state of } \\
\text { the requests in the common in-tray }\end{array}$ & $\begin{array}{l}\text { File (Case) allocation; } \\
\text { Team work }\end{array}$ \\
\hline $\begin{array}{l}\text { Flexible step allocation: one file } \\
\text { manager could execute } 5 \text { of } 9 \text { steps }\end{array}$ & $\begin{array}{l}\text { Flexible step allocation: one file } \\
\text { manager could execute } 6 \text { of } 11 \text { steps }\end{array}$ & Step Allocation \\
\hline $\begin{array}{l}\text { Strict definition of required data, } \\
\text { tools and activities within each step }\end{array}$ & No significant changes & Task flexibility \\
\hline \multicolumn{3}{|l|}{ Commercial Credits } \\
\hline Fixed routing & No significant changes & Routing \\
\hline $\begin{array}{l}\text { Common in-tray for analyst } \\
\text { Personal in-tray for account manager }\end{array}$ & No significant changes & $\begin{array}{l}\text { File (Case) allocation; } \\
\text { Team work }\end{array}$ \\
\hline $\begin{array}{l}\text { Strict step allocation: one or two } \\
\text { steps for one role }\end{array}$ & Idem & Step Allocation \\
\hline $\begin{array}{l}\text { Strict definition of data and activities } \\
\text { within each step }\end{array}$ & $\begin{array}{l}\text { More freedom to enter the data } \\
\text { according to the real needs and } \\
\text { availability. More freedom to re-open } \\
\text { requests after a re-negotiation }\end{array}$ & Task flexibility \\
\hline
\end{tabular}

It is important to remark that within the workflow community, workflow systems are known to have typical functionalities such as: the routing of work items throughout the process, the allocation of steps to roles, and the distribution of work items within a "role" ("actor assignment") (Poelmans, 2002, Joosten et al. 1994). When studying workflow flexibility, we started with this scheme. As discussed above, we also focused on the potential to increase flexibility by designing a more fine-grained step definition.

During our study however, it became clear that another kind of flexibility should be considered: task flexibility. In the literature, workflow systems are often defined as coordinators that route and allocate work items to human actor or computer applications, without interventions into the contents of the tasks to be done. In our case studies however, we noticed that a workflow system can be applied to steer and determine how a 
task should be performed, by controlling the required data entry (and also the access to supporting tools and databases). In the commercial credits process, this usage turned out to be a critical factor, influencing the suitability of the application.

Looking at the different flexibility parameters in parallel, we state that the actual configuration of the workflow system is a critical success factor. In the case of Finco, the technology itself does not impose its internal mechanisms (or the "agenda" of the management) on the end-user, but could be adjusted to reflect the needs of the end-users.

In accordance with Bowers et al. (1995), we agree with them on a more general level that a workflow system and its tools should not be different from the tools used in the work. In all our case studies, the workflow technology was not implemented next to existing tools, rather, many efforts were done to integrate or even replace legacy systems with(in) the workflow applications. Nevertheless, as mentioned by Bowers et al. (1995), internalizing the work in the workflow system can also be prohibiting to the end-users (cf. also De Michelis and Grasso, 1994). Particularly case study X shows that this might lead to a low degree of task flexibility, impairing the smooth flow of work.

Overall, we are convinced that administrative processes are the more natural habitat for such systems considering the various workflow implementations we have come across. As we hope to have shown in the presentation and evaluation of our studies, we propose that workflow technology is configurable to such an extent that implementation success is rather determined by management and design choices, than actually constrained by workflow system characteristics.

\section{Conclusion}

The EP case study has been a pioneering effort to better understand the relation between work practice and the properties of workflow technology supporting that work and its coordination. We have argued in this paper that there are two main reasons that similar difficulties are less severe in contemporary settings of workflow implementations.

The first one is that most commercially available workflow systems are intended to and also used to support administrative processes. Here, make-to-stock is a rarity - if not an impossibility - and as a consequence anticipation of work is less common. The implementation of a workflow system will therefore not hinder the "jumping the gun" practice. Our three studies into workflow implementations support this view.

The second factor is that managers and designers of the process definitions have a large impact on the flexibility that can be offered in allocating work. Configuration choices such as a smaller distinctions of steps in process definitions or applying shared in-trays may result in more run-time flexibility. On a minor note, we feel that it would be rather unfair to criticize the overhead a workflow system generates on administrating the various jobs, when this is exactly the type of information that one would like to extricate from such a system. This, more reasonably, is one of the 'provisos' Bowers et al. (1995) speak of that a company has to account for when it wishes to reap the benefits of workflow technology. 
Our main conclusion is that workflow technology is configurable to such an extent that implementation success is to a large extent determined by management and design choices. At the same time, workflow technology is still far from perfect. A major problem encountered throughout all studies is the difficulty to integrate workflow systems with existing legacy systems. For example, for the asset managing company involved in study $\mathrm{Z}$ (see Table 1) the poor integration resulted in an actual project duration that exceeded the planned one with $80 \%$ and a budget overrunning of $40 \%$. It should be noted that the integration issue was already addressed in the seminal paper by Georgakopoulos et al. (1995), which shows that remarkably little progress has been made here. It needs to be seen whether the advent of web services, standardized mark-up languages for data exchange, and service oriented architectures will remedy this situation.

Our hope is that with this work we have contributed to contribute to a more balanced and contemporary interpretation of EP case study and the appreciation of workflow technology in general. In our opinion, workflow technology is an increasingly powerful aid for all kinds of companies, which nonetheless remains open for many improvements. Ongoing fieldwork reporting on case studies that involve modern workflow technology will continue to be a necessity to test and refine its underlying concepts.

\section{Acknowledgements}

The running study $\mathrm{Y}$ into the effectiveness of workflow management systems referred to in this paper is research jointly carried out with Deloitte in The Netherlands.

\section{References}

1. L. Aversano, G. Canfora, A. De Lucia and S. Stefanucci, Journal of Software Maintenance and Evolution Research and Practice 14: 4 (2002) 229-255.

2. J. M. Bowers, The Work to Make a Network Work, in Proceedings of the Conference on Computer Supported Cooperative Work (CSCW'94), ACM Press, Chapel Hill, 1994, pp. 287298.

3. J. M. Bowers, G. Button and W. Sharrock, Workflow from Within and Without: Technology and Cooperative Work on the Print Industry Shopfloor, in Proceedings of the Forth European Conference on Computer-Supported Cooperative Work (ECSCW'95), Kluwer, Dordrecht, 1995, pp. 51-66.

4. F. D. Davis, MIS Quarterly 13: 3 (1989) 319-340.

5. G. De Michelis, and M. A. Grasso, Situating Conversations within the language/action perspective: The Milan Conversation Model, in Proceedings of the Conference on ComputerSupported Cooperative Work (CSCW '94), ACM Press, Chapel Hill, 1994, pp. 89-100.

6. P. Dourish, Process Descriptions as Organisational Accounting Devices: The Dual Use of Workflow Technologies, in Proceedings of the 2001 International ACM SIGGROUP Conference on Supporting Group Work (GROUP'01), ACM Press, New York, 2001, pp. 5260 .

7. P. Dourish, J. Holmes, A. MacLean, P. Marqvardsen and A. Zbyslaw, Freeflow: Mediating Between Representation and Action in Workflow Systems, in Proceedings of the Conference on Computer Supported Cooperative Work (CSCW '96), ACM Press, Boston, 1996, pp. 190198.

8. L. Fischer (ed.), Workflow Handbook 2001 (Future Strategies, Lighthouse Point, 2001). 
9. R. D. Galliers, in Information Systems Research - Issues, Methods and Practical Guidelines, ed. R. D. Galliers (Blackwell Scientific Publications, Oxford, 1992), pp. 144-162.

10. D. Georgakopoulos, M. Hornick and A. Sheth, Distributed and Parallel Databases 3 (1995) 119-153.

11. P. M. J. Giesberts and L. van Tang, Production Planning \& Control 3:3 (1991) 300-313.

12. T. Harder and A. Reuter, Computing Surveys 15:4 (1983) 287-317.

13. J. Harris and A. Henderson, A Better Mythology for System Design, in Proceedings of the Conference on Human Factors in Computing Systems: The CHI is the Limit (CHI'99), ACM Press, New York, 1999, pp. 88-95.

14. S. Joosten, G. Aussems, M. Duitshof, R. Huffmeijer and E. Mulder, WA-12: An Empirical Study about the Practice of Workflow Management (University of Twente, Enschede, July 1994).

15. J. Ljungberg, P. Holm and A. Hedman, Information Technology and Organizational Effects: Supporting the Sales Process with Workflow Technology, in Proceedings of the 1997 Conference on Computer Personnel Research (SIGCPR '97), ACM Press, New York, 1997, pp. 171-179.

16. M. Lousa, A. Sarmento and A. Machado, Expectations towards the Adoption of Workflow Systems: The Results of a Case Study, in Proceedings of the Sixth International Workshop on Groupware (CRIWG 2000), IEEE Computer Society Press, Madeira, Portugal, 2000, pp. 3641.

17. W. Orlikowski, Learning from Notes: Organizational issues in groupware implementation, in Proceedings of the ACM Conference on Computer Supported Cooperative Work (CSCW'92), ACM Press, New York, 1992, pp. 362-369.

18. E. A. H. Platier, A Logistical View on Business Processes: Concepts for Business Process Redesign and Workflow Management. PhD Thesis, Eindhoven University of Technology, Eindhoven, 1996.

19. S. Poelmans, Making Workflow Systems Work. An Investigation into the Importance of Taskappropriation Fit, End-user Support and other Technological Characteristics. PhD Thesis, Katholieke Universiteit Leuven, 2002.

20. S. Poelmans, SIGGROUP-Bulletin 20:3 (1999) 11-12.

21. W. Prinz and S. Kolvenbach, Support for Workflows in a Ministerial Environment, in Proceedings of the ACM Conference on Computer Supported Cooperative Work (CSCW'96), ACM Press, New York, 1996, pp. 199-208.

22. H. A. Reijers and W. M. P. Van der Aalst, International Journal of Information Management 56:5 (2005) 457-471.

23. H. A. Reijers, J. Rigter and W. M. P. Van der Aalst, International Journal of Cooperative Information Systems 12:3 (2003) 365-391.

24. K. H. Rolland and J. Herstad, The Critical Case in Information Systems Research, in Proceedings of the 23rd Information Systems Research Seminar in Scandinavia: Doing IT Together (IRIS23), Laboratory for Interaction Technology, University of Trollhättan Uddevalla, 2000, pp. 213-223.

25. W. M. P. Van der Aalst and K. M. van Hee, Workflow Management: Models, Methods and Systems (MIT Press, Cambridge and London, 2002).

26. W. M. P. Van der Aalst and P. J. S. Berens, Beyond Workflow Management: Product-Driven Case Handling, in Proceedings of the 2001 International ACM SIGGROUP Conference on Supporting Group Work (GROUP'01), New York, 2001, pp. 42-51.

27. G. Walsham, Interpreting Information Systems in Organisations (Wiley \& Sons, Chichester, 1993). 